\title{
Virtual Fort Gibson: Footsteps through the frontier
}

\author{
Cheyanne Wheat \\ Tandy School of Computer Science, \\ University of Tulsa \\ 800 S Tucker Drive \\ Tulsa, OK 74104, USA \\ cgw4639@utulsa.edu
}

\author{
Robert Pickering \\ Department of Anthropology, \\ University of Tulsa \\ 800 S Tucker Drive \\ Tulsa, OK 74104, USA \\ bob-pickering@utulsa.edu
}

\author{
J. C. Diaz \\ Tandy School of Computer Science, \\ University of Tulsa \\ 800 S Tucker Drive \\ Tulsa, OK 74104, USA \\ diaz@utulsa.edu
}

\section{INTRODUCTION}

This project investigates the fusion of interactive technology with accurate digital reconstructions of historical sites. Specific focus of this project is Fort Gibson (Oklahoma) in 1841 when it was the United States southwestern forward post. This project incorporates archaeological and anthropological data to create an accurate representation of the fort as a locale to layer on interactive activities. The end goal is to create an interactive history-based exhibit that appeals to and engages new audiences.

To construct Virtual Fort Gibson, Unreal Engine is used to create the landscape and overall firstperson interaction. The topographical information is extracted from Google Maps data. Blender 3D modelling software is used to construct artefacts and building architecture including soldier's quarters, block houses, and stockade. The objective is to allow the user to explore the fort, see objects of the period and learn about life in the 1840 s in the frontier. As an interactive activity, the player can engage in time-accurate miniinteractions and explore room interiors.

The data and objects that are part of this virtual model come from historic documents and maps (Gilcrease Museum, Tulsa, OK and the McFarlin Library, University of Tulsa), paintings, and archaeological excavations (Oklahoma Archaeological Survey).

\section{FORT GIBSON ON THE FRONTIER}

The focus of this project is Fort Gibson on the shores of the Arkansas River in Oklahoma territory as it appeared in 1841. The 1830 Indian Removal Act by the United States government forced the removal of Native Americans from their ancestral homelands in the eastern United States to lands west of the Mississippi River to a designated Indian Territory -roughly, modern Oklahoma. Most of these migrations were completed from 1831-38 (Clark 2012). Across the border to the South and West of Oklahoma Territory was the Republic of Texas. It became independent of Mexico in 1833 and would join the U.S. in 1945. In 1841 Fort Gibson was the United States southwestern forward post.

\subsection{Historical figures at Fort Gibson}

Many figures passed through Fort Gibson during its peak. Senior officers served there. A wide range of young officers saw time at this western fort. Some became notable during the Civil War, including Jefferson Davis. Capt. Nathan Boone, son of Daniel Boone served at Gibson and helped guide the expedition of Josiah Gregg, who mapped and chronicle of life on the Plains. George Catlin, an American painter, author, and traveller who is recognised for his portraits of Native Americans. His paintings, sketches and letters reveal much about life at Ft. Gibson and the Plains west of there. Many of his paintings are located at the Gilcrease Museum in Tulsa, Oklahoma.

\section{LIFE AT THE FORT}

Three documents of the period have been pivotal resources. Marcus Claudius Marcellus Hammond wrote a diary (Hammond 1841) regarding his buffalo hunt along the Canadian River. John Flynn a Private of Dragoons who was at the fort between 1839 and 1844 wrote his Reminiscences' (Flynn 1984). Fort Surgeon, Dr. Motte created a ledger of his patients for 1844 (Motte 1844). We observed diary entries from a soldier during his time at Fort Gibson. He recalls his interactions, costs of shopping, and various daily life activities. From these accounts, we craft a narrative to follow to Hammond's experiences. 


\section{TECHNOLOGY}

Virtual Fort Gibson was constructed in Unreal Game Engine (Unreal 2012) utilising other software such as Blender (Blender 2017). The virtual experience opens as a PC application, which can run on any modern desktop computer. This allows for the experience to be controlled by a desktop computer and shown via a large monitor.

\subsection{Development}

The landscape and creation of the fort's structure (architecture, etc.) was established first. The topography was extracted from Google Maps data and imported into Unreal Engine. Museum professional's input also included a desire to explore building interiors, to eat and interact with historic figures, to see living conditions, to experience the daily life, to play games, and to learn about important site history. Hence, the narrative implements historic significance and figures into the virtual experience.

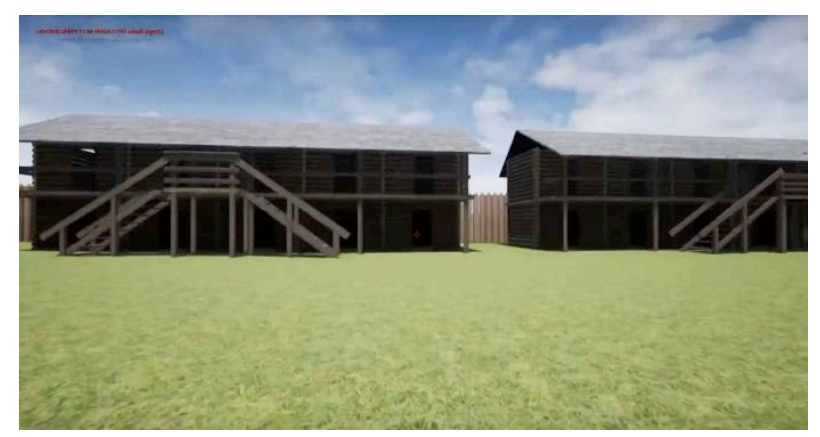

Figure 1: An inside view of the Fort.

\subsection{Virtual Fort Gibson}

Virtual Fort Gibson is a first-person exploration tool for viewers. The player can walk around the grounds of Fort Gibson. The buildings are built to correct scale in Engine. The player can also explore a few room interiors of bachelor's quarters and the armoury. The rooms are populated with time accurate furniture and other domestic artefacts. The player can also visit the Blockhouse at the edge of the Fort to look upon the horizon and nearby Arkansas River.

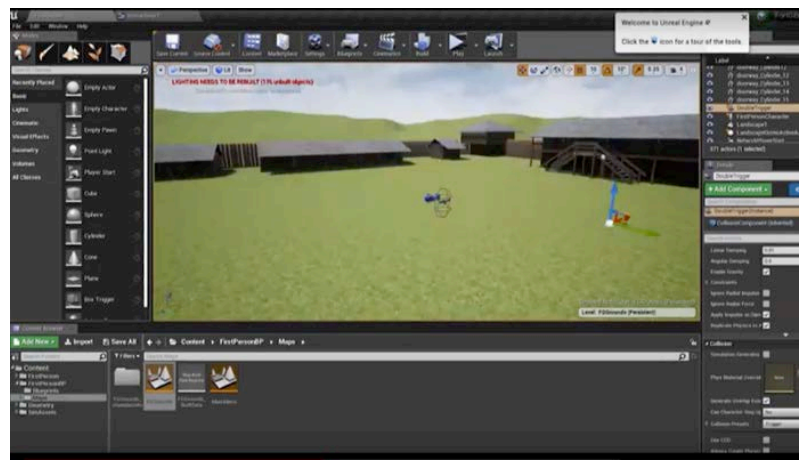

Figure 2: A detailed view of Fort Buildings.

\subsection{The narrative}

We decided to establish a playable narrative to engage players in a videogame-like experience. The player will be motivated through in-game "hotspots" and dialogue. The narrative was established as a linear structure in order to walk players through an "average" day at Fort Gibson.

\section{REFERENCES}

Blender (2017) Blender version 2.8, https://www.blender.org/ (retrieved 17 March 2020).

Clark, B. (2012) Indian Tribes of Oklahoma: A Guide. University of Oklahoma Press, Norman, Oklahoma.

Flynn, J. (1844) "Reminiscences of Some Incidents in the Career of an United States Dragoon Between the Years 1839 and 1844." (1981.008.3), McFarlin Library, University of Tulsa, Tulsa, Oklahoma.

Hammond, M. C. M. (1841) Diary, (3626.151), Helmerich Center For American Research, Gilcrease Museum, Tulsa, Oklahoma.

Motte, J (1844) Patients ledger for 1844, (4026.5925), McFarlin Library, TU) of his for 1844

Unreal (2012) Unreal version 3.8, https://www.unrealengine.com/en-US/ (retrieved 17 March 2020). 